\title{
Probing the Interplay Between the Public Sphere and Cyber Sphere Saga for Political Mobilization Among the Youth Community in Ethiopia
}

\author{
Solomon Tabor \\ Department of Journalism and communications, Dilla Universit/Ethiopia \\ PO box 38 Dilla university Ethiopia
}

DOI: $10.7176 / \mathrm{NMMC} / 79-01$

Publication date: April $30^{\text {th }} 2019$

\section{I.INTRODUCTION}

Over a period of time, human communication has gone through a lot of advancement. As literatures point out, the advancement has shown a gigantic development from oral tradition to written culture through scripting, printing, and to the electronic world through wired electronic communication, wireless electronic communication and to today's digital communication the so called the New Media. The recent information and technological revolution has changed the way in which People interact, communicate and share information; to this end Auer explained it as "vehicles that allow ordinary people to enter and influence many arenas of public life" (Auer, 2011:709).

With regards to the newness in new media, the key differentiating factor in terms of these new media is their highly interactive quality. The original uses of the internet include the more traditional web page format which allows users to only access information. These are referred to as unidirectional platforms and they are similar to traditional media such as newspapers and television. Social media platforms on the other hand are multi-directional or interactive

Internet has been transforming the use of traditional media and providing a new and interactive system of communication. Regarding to the fundamental influence the new media has on human Communication process Croteau and Hoynes (2003:322) states that the new media has:

- Altered the meaning of geographic distance.

- Allowed for a huge increase in the volume of communication.

- Provided the possibility of increasing the speed of communication.

- Provided opportunities for interactive communication.

- Allowed forms of communication that was previously separate to overlap and interconnect.

With regards to the strong interdependence between politics and the new media in this digital era, Polat (2005: 435) examines it interms of three facets: i.e the internet as an information source, a communication tool and a virtual public sphere. It is obvious that the new media has been serving as an information source quite more than any other communication out lets.

There is no doubt that too it is a tool of communication. A huge academic effort will be made in this particular study to emphasize the third facet, which is its role as a virtual public sphere. The hyper-textual, interactive, immediacy and other peculiar characteristics of the new media have made it a suitable public sphere (cyber sphere).

Since this study principally focuses on the role of the new media on political mobilization, it's imperative to look into literatures associated to it. Consequently, According to Enjolras, Steen-Johnsen, \& Wollebaek, (2012:17) political mobilization refers to "the process by which candidates, parties, activists, and groups induce other people to participate in politics to win elections, to pass bills, to modify rulings and to influence policies". Hence,the term political mobilization can be defined as the process through which citizens or activists induce one another through the medium of the internet and social media to participate in politics and specifically with the intention of influencing politics.

\section{PUBLIC SPHERE}

\subsection{Gist of the theory}

The public sphere as it is now known was established in the 18th century with the growth of public meeting places. Coffeehouses, literary societies and a free press were all meeting places or outlets where issues of public concern could be discussed. The concept of a 'public sphere', developed in its most advanced form by Jurgen Habermas, unambiguously placed 'undistorted communication' at the centre of the schema: By 'the public sphere' we mean first of all a realm of our social life in which something approaching public opinion can be formed. Access is guaranteed to all citizens. . (Habermas 1962: 198)

A portion of the public sphere comes into being in every conversation in which private individuals assemble to form a public body. They then behave neither like business or professional people transacting private affairs, 
nor like members of a constitutional order subject to the legal constraints of a state bureaucracy. Citizens behave as a public body when they confer in an unrestricted fashion - that is, with the guarantee of the freedom of assembly and association and freedom to access and publish their opinions - about matters of general interest. In a large public body this kind of communication requires specific means of transmitting information and influencing those who receive it. Today newspapers and magazines, radio and television are the media of the public sphere. (ibid)

The public sphere is the concept of open dialogue where public opinion is formed. The public sphere is a concept of a community gathering to share information and form opinions. According to Habermas, "[t]he bourgeois public sphere may be conceived above all as the sphere of private people come together as a public"(Habermas 1962: 27).

The public sphere is no one place, though it is often associated with public forums. The concept is also related to the marketplace of ideas, a concept that if all ideas, good and bad, are shared, the truth will out. The public sphere was originally proposed by cultural theorist Jürgen Habermas in 1962. The ideal public sphere is made of private people gathered as a public to discuss the needs of society to the state, the ruling force. Through assembly and dialogue, the public generates opinions about the role of the state, either challenging or affirming the status quo. The public then articulates its opinions to the state. This dialogue makes up public opinion. Cultural theorists agree that public opinion is vital for a legitimate democracy. (http://www.ehow.com)

\subsubsection{The Structural Transformation of the Public Sphere}

The structural transformation of the public sphere can be considered as a manifestation of the historically contingent nature of social order. Both the rise and the potential demise of the public sphere indicate that the transformative potential of public realms of intersubjectivity cannot be separated from the developmental nature of society. Put differently, the transformation of the public sphere has to be examined in terms of the wider context of macro structural transition processes. Thus, the history of the public sphere should not be treated as a free-floating development divorced from wider social processes; rather, it should be conceived of as integral to these processes (Thompson 1995: 71)

\subsubsection{Main assumptions}

* The principles of the public sphere involved an open discussion of all issues of general concern in which discursive argumentation was employed to ascertain general interests and the public good.

* The public sphere thus presupposed freedoms of speech and assembly, a free press, and the right to freely participate in political debate and decision-making.

* Habermas asserts that an element or portion of the public sphere comes into being when (even just a few) people gather together as citizens to discuss matters of common interest.

* Disregard of status - status for participation was disregarded altogether

* Domain of common concern- the agenda was of 'common concern'

* Inclusivity

\subsubsection{Its importance}

Calhoun stressed the societal importance of the public sphere in such a way that "the importance of the public sphere lies in its potential as a mode of societal integration" (1992: 6). Hence besides idea deliberation, the public sphere had/has a big role in consolidating the societal integration and social well being. Besides, the following points are among the merits of the theory.

* The theory, discourse or idea is essential in that it vividly shows how public opinion can be formed and crystallizes through pervasive public spheres.

* Open and operational public spheres help progress and thrive democracy

* It also contributes to the field of JOCO in such a way that through consolidating freedom of expression and an open communication.

* Updates people on world events

* Help to make informed decisions

* Help to avoid pseudo democracy.

True public sphere help as an indicator of a society's democratic well being.

\section{III.Towards the virtual public sphere/ 'Cyber sphere'}

The new media has brought about a social dynamics that impact the way individuals negotiate their views on public matters to produce some form of public opinion. As Dounia Mahlouly put it Applying Habermas' theory to the digital and connective culture of the twenty-first century shows that one of the most significant differences between the emergence of the bourgeois public sphere and the liberalization of online public discourses lies in the intellectual leadership. Whereas publicity and public opinion were led by members of the bourgeois elite in the period that preceded the French Revolution, every citizen now has access to the public scene. Interestingly this is probably the reason why digital technologies appear to be prominent in democratizing countries. $(\mathrm{p} ; 18)$. 


\subsection{The ideological connotations of the 'new' in the new media}

Martin and his associated in their book called, new media: a critical introduction endeavored to unlock the term 'new' in the new media from the stand point of ideological connotative. They asserted that the strongest sense in which the 'new' in new media carries the ideological force of 'new equals better' and it also carries with it a cluster of glamorous and exciting meanings. The 'new' is 'the cutting edge', the 'avant-garde', the place for forward-thinking people to be (whether they be producers, consumers, or, indeed, media academics). These connotations of 'the new' are derived from a modernist belief in social progress as delivered by technology. The authors explained as to how and by whom this narrative is subscribed. According to them, the narrative 'new' is bought by not only by the entrepreneurs, corporations who produce the media hardware and software in question, but also by whole sections of media commentators and journalists, artists, intellectuals, technologists and administrators, educationalists and cultural activists. (Martin Lister, et al.., 2003: 11)

Moreover, the authors have avowed concerning the currency of the term new media in a way that 'New media' has gained currency as a term because of its useful inclusiveness. It avoids, at the expense of its generality and its ideological overtones, the reductions of some of its alternatives. It avoids the emphasis on purely technical and formal definition, as in 'digital' or 'electronic' media; the stress on a single, ill-defined and contentious quality as in 'interactive media', or the limitation to one set of machines and practices as in 'computer-mediated communication' (CMC). So, while a person using the term 'new media' may have one thing in mind (the Internet). (ibid, 2003: 11)

\subsection{Characteristics of the new media}

In their book called New Media - A critical Introduction (p 13-37), Martin Lister and his associates has come up with six main characteristics of the new media. These are: simulated, virtual, networked, hypertexual ,digital and interactive.

\section{$>$ Simulated}

A simulation is certainly artificial, synthetic and fabricated but it is not 'false' or 'illusory'. Processes of fabrication, synthesis and artifice are real. Simulations are real, they exist, and are experienced within the real world which they augment.

\section{$>$ Virtual}

Virtual worlds, spaces, objects, environments, realities, selves and identities, abound in discourses about new media. Indeed, in many of their applications, new media technologies produce virtualities. While the term 'virtual' (especially 'virtual reality') is readily and frequently used with respect to our experience of new digital media it is a difficult and complex term. In this section we make some initial sense of the term as a characteristic feature of new media.

\section{$>$ Networked}

New media are networked at the level of consumption where we have seen a multiplication, segmentation and resultant individuation of media use; dispersed at the level of production where we have witnessed the multiplication of the sites for production of media texts and a greater diffusion within the economy as a whole than was previously the case.

\section{$>$ Hypertextual}

The prefix 'hyper' is derived from the Greek 'above, beyond, or outside'. Hence, hypertext has come to describe a text which provides a network of links to other texts that are 'outside, above and beyond' itself. It is a web of connection which the user explores using the navigational aids of the interface design. Each discrete 'node' in the web has a number of entrances and exits or links.

\section{$>$ Digital}

By digital, it implies that all input data are converted into numbers. In terms of communication and representational media this 'data' usually takes the form of qualities such as light or sound or represented space which have already been coded into a 'cultural form' (actually 'analogues'), such as written text, graphs and diagrams, photographs, recorded moving images, etc. These are then processed and stored as numbers and can be output in that form from online sources, digital disks, or memory drives to be decoded and received as screen displays, dispatched again through telecommunications networks, or output as 'hard copy'.

\section{$>$ Interactivity}

The interactive feature of the new media is explained in the book that at the ideological level, interactivity has been one of the key 'value added' characteristics of new media. Where 'old' media offered passive consumption new media offer interactivity. Generally, the term stands for a more powerful sense of user engagement with media texts, a more independent relation to sources of knowledge, individualized media use, and greater user choice. 


\subsection{Renovation of media in the digital age:}

Pavlik (2008:25) mentions that the transformation of media in the digital age involves at least twelve dimensions. They are:

1. The medium of digital delivery;

2. The devices for accessing, displaying, watching and listening to digital media;

3. The audience or users of digital media;

4. The producers of digital media;

5. Digital media content itself;

6 . The distributors of media;

7. The financers, owners and business of media;

8. The regulators and law of media;

9. The digital technologies of production (and encryption) that in many ways are fuelling the explosive growth in media production and protection;

10. The inventors and innovators of next generation media;

11. The ethical framework surrounding or providing context for media;

12. The next generation of media consumers, users and creators

\subsection{Politics and the internet}

According to Farrell, in the future the relationship between the internet and politics will become increasingly important to analyze and understand. He states that "paradoxically, it is likely that there will be ever fewer scholars specializing in the internet and politics...this will not be because political scientists will lose interest in the internet and related technologies.

Rather, it will be because these technologies will have become so integrated into regular political interactions that it will be impossible to study" (Farrell, 2012: 47).

Polat (2005: 435) examines the relationship between the internet and political participation by deconstructing the internet into three facets. The article examines the internet as an information source, a communication tool and a virtual public sphere. Polat does not arrive at any definitive conclusions concerning the link between the internet and political participation. It is stated that even though the internet may provide access to large quantities of information it is reliant on the assumption that citizens have a strong enough desire that they seek out the information and that all citizens have equal access to the internet.

With regards to the effects of SNS on authoritarian regimes, Lynch asserted that the effects of social media networks and their effects on authoritarian regimes seem adversarial. He states that "...Networked communication fundamentally challenges existing social and political orders, privileging horizontal networks over hierarchical organizations such as the modern nation-state" (Lynch, 2011: 303).

\section{IV.Loom of cyber sphere in Ethiopia}

The use of the internet in Ethiopia began in 1993 when the UN economic commission for Africa established an e-mail service called PADISNET (Pan African Documentation and Information Service Network). The facility was heavily used by international organization and NGOs, and also by some academics, individuals and private companies. At its peak, the service had about 1200 users. (International telecommunication union; 2002:6)

In 1996, a broadly cross-sectoral national internet working group supported by Ethiopian science and technology commission (ESTC), drafted a detailed national internet proposal and it was realized in January 1997 by ETC (Ethiopian Telecommunication Corporation). Within a month of its launch Ethionet had 600 users. (ibid). According to internet world status report, the internet penetration rate in the Ethiopian in 2017 is around $16,000,000$ which is $15 \%$ of the total population. (internetworldstatus.com). with regards to facebook subscribers, the numbers of active users are around 4.5 million (ibid).

Though the numbers of active social media users are low in Ethiopia compared to the total population, and majority of African countries, its impact over the last four years have been tremendous. This was partly because the suitability of the media to communicate, according to Kaplan, Social media allows citizens to communicate, debate, share video and photographs across distances of both space and time. The web is providing entirely new tools and resources to track and cover world politics. Web 2.0 is the base upon which social media were built and these social media sites have provided a new way in which large sectors of the population participate in politics (Kaplan \& Haenlein, 2010: 61).

\section{Blessings and nuisances of the cyber sphere/social media in Ethiopia}

The new media has given birth to the rising citizen journalism. Consequently, user generated content (UGC) such as photos, videos from the cyber community has become very common and popular among the public predominantly among the youth community. Its newness by itself invites citizens to get try of it, its modern appliances invites to acquaint oneself with technology, its interactive feature magnetize to be addicted to, its free 
access to public information pulls towards it. In spite of its mesmerizing features, however, it has served as part of the causes for conflicts. Some individuals while hiding their identity used the e-media to spread hatred distort information; forge pictures and videos, extensively engaged in spreading information out of their context. The border line between freedom of expression and misinformation seems to be blurred by majority to the online users; ethical frauds have become common with in the new media. And this has damaged the shared values of the society. Due to the disrespectful interactions, hate speech, and unaware and uncivilized use of the platform, the harmony among nations and the shared values have been dented.

Over the last couple of years, social media has been a melting pot for political mobilization among the youth community. Due to the very fact that the main stream media had been heavily dominated by the government in power; the new media particularly the social media and more particularly facebook had been serving as the main alternative media for the youth to participate and to mobilize and being mobilized in politics. The use of social media has changed the balance of power in a way that enabled citizens to massively influence the regime. Face book has been instrumental in steering up the political mobilization of the youth group in Ethiopia.

Almost in every part of the country, especially in oromia and amhara regions, where internet could be accessed, there had been an active political mobilization particularly by the youth group led by social media activists. The social media had been used, still is, an alternative and free political forum.

During the times of heighted political polarization, tense ethnic divides, and when the public is dissatisfied with the mainstream media, the public, the youth in particular, will massively be dependent on the cyber information and the impacts of the social media could be multiplied and multifaceted. Along with it, the public faces all the blessings and blessing in disguise of the social media and other consequences. Its impact was so potent that the government was forced to take measures ranging from slowing down the connection and ceasing the mobile data to the extremes of shutting down the internet connection. However, due to the fact that the online messages were hastily spread out, it was translated into an actual public sphere arena. And public spaces became political spaces and the unrest continued. As a result the government was obliged to declare state of emergence. Hence, that was an evident that the online messages have been translated into offline actions

The contents of the online/social media messages that caused all those cyber war along the thin ethnic and political lines exacerbated the actual political tension on the ground. Though the social media is quite young in the country, its impact over the last couple of years was beyond expectation. Potentials of the social media concerning its roles, prospects, associated challenges and its prospects for political mobilization among the youth age group was given quite the least attention by every stakeholder including the government in power. For the cyber sphere to be potentially malign or valuable, it has to be translated on the ground. Hence, the message online and its impact on the ground should critically be weighed. The ancillary nature of online and offline communication looms i.e. the cyber sphere Vs the public sphere saga is believed to result in the political mobilization surfaced almost all over the country.

\section{VI.Elucidating the saga of public and cyber sphere for political mobilization}

Though very young its emergence in Ethiopia, the social media, with all its superseding features, as a communication tool and a platform for political mobilization has made it ideal to make use of it and enabled citizens to participate in cyber politics. It has become so entrenched as a political communication tool in the country especially by the youth community. Overtime, its impact has becoming overwhelming. The impact of social media was massive in mass political mobilization in the last two years particularly in Oromia and Amhara regions. As a result of the politically persuasive messages mainly orchestrated by the SM activists, the youth has marched for mass movements on the ground.

Consequently, due to the awful measures taken by the government in power, Many had lost their lives, severely injured, fled from the country, and masses had been locked up in jail/ taken into custody.

Additionally, messages on the web have increasingly been translated into actions on the ground. The influence of active activists on the youth is being increasing from time to time. Being initiated and/or mobilized by SM activists, the youth is being observed to take actions. The harsh ethnic based cyber war on SM is a typical manifestation of it. As a result of mass circulation of ethnic based hatred messages on SM, it has contributed its part for mass displacement of citizens based on only of their ethnic identity.

As explained above and over, the impact of the new media has become a new problem. New challenges require new approaches. So this particular research argues that an old solution like shutting internet connection, slowing down connection and other totalitarian measures would not/ didn't yield a solution that leads to use the media for productive and democratic purposes. So a new participatory approach based on research out comes should be tried out. From time to time the SM has won the hearts of the able youth and they become a vibrant users and massive consumers of the media.

The digitization of all kinds of information such as speech, text, image and video, and the possibility of connecting everyone to everyone on the SM demands a detail and comprehensive study to come up with a viable 
solution for the catastrophes resulted by it. So all overt and covert factors should be unshadowed via research. All stakeholders, vibrant SM users, activists, responsible government offices, journalism intellectuals, should be reached out for a comprehensive solution. If used properly SM can be a chief ingredient in the effort towards creating an informed and responsible citizen.

\section{Compelling issues/questions of the cyber sphere in Ethiopia}

\subsection{Has it brought a new power shift?}

The main stream media has long been a power and central information dissemination vehicle in Ethiopia.

And citizens had no options but to tag along with the information given out by the main stream media. The dynamism, interactivity, hyper-textuality, networked features of the new media/ SM have brought about a power shift in information control that enabled an active participation of citizens. As Manuel Castell (2007:6) explained the new media as "mass self-communication", citizens who are able and have access to the technology made the new platform an arena of discussion and has changed it into a new political war front against the government in power. Though the mainstream media attempted to coup the challenge coming from the new vibrant media; it was all in vain. And it seems that the social media has brought about a new information power shift from the controlled mainstream media to a liberal social media and the youth has massively been attracted to, enjoyed and mobilized by the free flow of uncensored information of the social media.

\subsection{No ethics! So just pull the trigger and shoot with words}

The situation of using the social media in Ethiopia is more like a virtual battlefield. The face book pages are used as battlefields, and many of the activists are the war lords, their followers are their loyal soldiers, and words, pictures and videos are their bullets, and the political ideology, ethnic antagonistic groups are in war day in and day out. It seems the issue of ethics is seriously overlooked as if it doesn't exist. George Reynolds (2003:22) explained concerning the imperatives of media ethics in that it improve ethical decision-making, promote high standards of practice and ethical behavior, enhance the trust and respect from the general public, and it provide an evaluation benchmark.

Those imperatives when translated into the new media, one can clearly see the critical ethical violations. While the new media has made communication easier, faster and more accessible to everyone, and made users 'produser' that stands for user and producer simultaneously, the ethical issues has become a pressing issue.

Neelamalar (2010:54) has avowed concerning the new media ethical frauds. So all cyber ethical misconducts like cyber Data diddling (changing raw data), Morphing (editing the original pictures), Internet pharming (hijacking the victim's server and changing the IP), Hacking, Cracking, Virus, Cyber terrorism, Cyber defamation, cyber bullying and the likes have become a huge challenge in Ethiopia though common elsewhere too.

\subsection{Cyber sphere; new equalizer or divider?}

According to Maquail, the networks, circles and connections between users of new technology based on telecommunications and computers do not have to follow the lines of national frontiers in the same way as old mass media almost invariably have done. It may therefore be less appropriate to apply the "centre-periphery model" of mass communication which reflects the varying degrees of dependency in poorer and smaller countries and regions on a few 'primary producers' of news and entertainment. The possession of the right technology does open doorways to new possibilities for information and intercommunication, irrespective of the 'level of development of one's own home place. Some of the gaps and obstacles to development may be leapfrogged. Nevertheless, the great imbalance of communication capacity still exists, and exceptions apply only to a small minority for certain purposes.

Needless to say that the new media is a new communication opportunity for every able one to enjoy and equalize on the frontier of communication, however, it is observed that it has become a new divider. The concept in our country can be applied in such a way that the youth in particular is using it to create division along the lines of ethnicity, religion, political ideology, group loyalty and the likes. What went wrong with using it completely out of the aimed purpose and blindly support or oppose a certain issue, ideology, race.demands a careful scientific approach and research analysis. The knowledge, experience, cultural understanding, modern thinking gaps, and above all the ethnic divide between users of the new media have made it a divider than information sharing platform.

\subsection{New media- new question/challenge}

The main challenge concerning the new media is the credibility of information and facts. According to Callahan (2003:19) "the stunning growth of the new media has provided unprecedented reporting opportunities, and unprecedented peril. This is because of the proliferation of rumors and misinformation on the social networking sites." hence, the main challenges of using the new media, particularly the social media, for news consumption 
and distribution is that the concerns regarding accuracy, the need for verification and the loss of control over the information. Inaccurate information, wrong facts or exaggerated versions of information are the main risks.

\section{The interplay of cyber sphere and public sphere for political mobilization in Ethiopia 8.1. As an organizational tool}

The cyber and public sphere have been interplaying as an organized tool to bring about the political mobilization observed in the country. The illegal, immoral and unethical deeds of the government in power were tipped to face book activists by insiders and it will get light via face book and reach hundreds of thousands of followers. And the followers on therir turn spread the information via various public spheres, coffee houses, markets, liquor houses and the likes, to millions others. And the resultant effect of all those actions has given birth to political mobilization.

The efficient use of social media networks as a form of organizational infrastructure that began with virtual networks and was transposed to offline networks. Activists are able to successfully play off the strengths of the social networking capabilities of Facebook and Twitter by capitalizing on their "many-to-many" communication capabilities and the speed with which information can be transferred and spread, an inherent characteristic to any digital media.

Not only did the new media provide the organizational infrastructure, but also it provided a crucial platform for potential protesters to network with one another and shares their common grievances. Once individuals found out that other people would be protesting, they were more likely to join themselves. Eventually, a tipping point occurs, when the protest or activity becomes self-reinforcing, and increases without further direct organization or action by the leadership. Once the plans for demonstrations were put in place, word was spread throughout offline communities. It has been pointed out by some critics that social media cannot be attributed too much credit in spreading information in countries with low Internet penetration, as is the case with most Arab states. However, this ignores the role that social networking online plays in enhancing social networking offline. "Every user is a potential rebroadcasted to their own, real-world, social networks, and when Internet use is overwhelmingly concentrated among the young, as it is in most countries with low Internet penetration, there's minimal duplication in the bush telegraph system." The conclusion to be drawn from this example is that successful politically driven social movements must be based on grassroots

\subsection{As an alternative press}

As the main stream media in Ethiopia has long been controlled and even censored by the government, and almost all the private press, news papers and magazines, were shut down and journalists were thrown into prison and others more exiled, the cyber sphere, face book, has become a free media its attributes has accentuate it in Ethiopia. With all their limitations the cyber and public spheres were massively been used as an alternative tools for political mobilization in the country.

With its low entry barriers, social media tools provide an accessible platform for citizen journalism, defined as the use of digital media tools to report on events on the ground, uploading text and videos directly to the Internet or feeding the information and videos to media outlets. The dialogue taking place via Facebook, Twitter and other SMNs was used by the mainstream media as a source during the height of the protests.

The strategy worked by trying to identify key bloggers in countries before protests broke out, informed by the situation in other areas, to act as citizen reporters and then be able to verify information later on. Though there are obvious accuracy issues related to citizen journalism, the implication for the role of social media within the uprising is that it allowed for those directly involved to shape their own narrative and expose themselves to an international audience. Social media place "the tools of documentation and truth-telling into the hands of ordinary citizens, SMNs create linked activists who can contest the narrative-crafting and informationcontrolling capabilities of authoritarian regimes.

\subsection{As generating awareness}

So as to inflame the general public against an oppressive regime, raising the political awareness is detrimental. To this end, the cyber and public sphere amalgamation has played the greatest role. The general public seemed gradually awaken from political dizziness and the chains of fright as the two cyclic spheres interplayed aggressively. Almost everything, including the jokes and humors, on the social media were centered on politics and that raised the political awareness of the mass in a way to demand its rights in one way or another.

Much attention has been paid to the role that the Internet has played in generating awareness of the Arab Spring in both the Middle east and internationally. This is another example of how movements started online were transposed to offline movements where they gained momentum and attention. A poll by The Arab Social Media Report indicated that in Egypt, the majority of Face book users polled agreed that Face book was used most effectively to raise awareness of the causes of the movements within the country. The act of using the Internet to advance a political cause that is difficult to advance offline...the goal of such activism is often to 
create intellectually and emotionally compelling digital artifacts

\subsection{Enabled Group Mobilization}

The interplay between the two cyclic spheres has resulted in group mobilizations. Apart from giving the individual citizen the opportunity to participate in the political discussions, the combination of the two spheres has served as a platform for galvanizing group interests almost throughout the country. It is a well known fact that Citizens are more empowered for civic engagement when they operate in groups which give them greater bargaining power than when they act individually. In fact, the larger and/or more articulate such a group is, the better placed it could become to empower the citizens for effective civic engagement. Therefore, the mass political mobilization surfaced as a result of the interconnected effect of the two spheres.

\section{IX.Resultant effects of the interplay of the two cyclic spheres}

* Improved accessibility as it allows citizens to reach out to political leaders through different channels. The grievances of the public have been heard loud and clear and that created a supporting group from the executives body and thereby created a faction called 'reform agent' that currently rule the country.

* Dissemination of information became realized for decision-making and the transfer of knowledge to the citizens. As it is always the case that knowledge/information is power, the public have become equipped with it to protest against the government.

* Facilitated effective networking among the citizens and the creation of different forms of organizations and communities such as "Querroo" in Oromia region, "Fano" in Amhara region, "Zerema" in Southern region of 'Guraghe' zone "Berberatta" in Somalia region and the likes.

* Mobilized citizens around a common cause that is evil political strife and spurred social-political action.

\section{Bibilography}

Anaeto, S. G., Onabanjo, O. S. and Osifeso, J. B. (2008). Models and Theories of

Alan s. (1997). News and the public sphere: towards a history of news objectivity.

Amjad, A. (2012). Social media: from Innovation to revolution. Retrieved on 18/07/2012 from http://www.pakistantoday.com.pk/2012/01/25/comment/columns/social-media-from-innovation-torevolution/

Auer, M.R., 2011. The Policy Sciences of Social Media. Policy Studies Journal, 39(4), pp.709-736. Available at: http://doi.wiley.com/10.1111/j.1541-0072.2011.00428.x.

Bryman, A. (1984). Social Research Methods. New York: Oxford University Press. Benkler, Y. (2006), The Wealth of Networks, New Haven: Yale University Press.

Croteau, D\&Hoynes, W. (2003) Media Society: Industries, Images and Audiences (third edition)

Chebib, Nadine Kassem \& Rabia Minatullah Sohail. "The Reasons Social Media Contributed to the 2011 Egyptian Revolution," International Journal of Business Research and Management 3 (2011).

Dalton, R. J. (2002). Citizen politics: Public opinion and political parties in advanced industrial democracies (3rd ed.). New York: Chatham House

Dahlgren, P., 2007. 'Introduction: Youth, Civic Engagement and Learning via New Media, in Dahlgreh, P. (ed.), Young Citizens and New Media, London: Routledge

Farrell, H., 2012. The Consequences of the Internet for Politics. Annual Review of Political Science. Available at: http://www.annualreviews.org

Friend. C \& Singer. J. (2007). Online journalism ethics- traditions and transitions

Finlayson, J.G. 2005. Habermas: A Very Short Introduction. Oxford \& New York: Oxford

University Press

Fenton, Natalie, and Veronica Barassi. "Alternative Media and Social Networking Sites: The Politics of Individuation and Political Participation.” The Communication Review 14 (2011): 179-196. Print.

Habermas, Jurgen. "Political Communication in Media Society: Does Democracy Still Enjoy an Epistemic Dimension? The Impact of Normative Theory on Empirical Research."Communication Theory 16.4 (2006): 411-426. Print.

Habermas, J?rgen (1964) 'The public sphere', in Armand Mattelart and Seth Siegelaub (eds.) (1979) Communication and Class Struggle, Vol. 1: Capitalism, Imperialism, New York, NY: International General. 476 Development

Habermas, J?rgen (1996) 'Civil society and the political public sphere', in J?rgen Habermas (translated by William Rehg) Between Facts and Norms: Contributions to a Discourse Theory of Law and Democ racy, Cambridge, MA: MIT Press.

Heinonen.A (2005). Journalism online- Ethics as usual

Himelboim, I. et al., 2012. Social Media and Online Political Communication: The Role of Interpersonal Informational Trust and Openness. Journal of Broadcasting \& Electronic Media, 56(1), pp.92-115. 
Available at:http://www.tandfonline.com

Joseph K, Mills C, Ellen M, \&Mills C. (2014) Youth, New Media, and the Rise of Participatory Politics Institute for Advanced Study

Jenkins, H. (2006) Convergence Culture, Where Old and New Media Collide London.

New York University Press.

Kaplan, A., \& Haenlein, M. (2009). Users of the world, unite! the challenges and opportunities of social media. Kelley School of Business, Indiana University.

Kothari. C.R. (2004), Research methodology; methods and techniques. New age international publishers $\left(2^{\text {nd }}\right.$ edition)

Latzer, M. (2009), 'Convergence revisited: Toward a Modified Pattern of Communications

Lusoli, W. \& Ward J. (2004).Country Report for the Internet and Election project, 2004 EuropeanParliament election UK component., report, Internet and Elections project.

Lynch, M., 2011. After Egypt: The Limits and Promise of Online Challenges to the

Authoritarian Arab State. Perspectives on Politics, 9(02), pp.301-310. Available at:

http://www.journals.cambridge.org

Madeline S.(2011), The Role of Social Media in Political Mobilization-

Martin Lister, John D. Seith G. jain G. Kieran K. (2009). New media: a critical introduction

McQuail, D. and K. Siune (eds) (1998), Media Policy: Convergence, Concentration and Commerce, London, Thousand Oaks, New Delhi: Sage.

McCombs M.E. and Shaw D.L, The agenda setting function of mass media, Public Opinion Quarrer Communication. Maryland, USA. Africa Renaissance BooksIncorporated.

McGuire, A.J. (1985). Attitudes and attitude change. In G.Lindzey \& E.Aronson (Eds.), The handbook of social psychology: Vol2. Special fields and applications (3rd ed., pp. 233-346). New York: Random House.

McGuire, W.J. (1986). The myth of massive media impact: Savagings and salvagings. In G.Comstock (Ed.), Public communication and behavior

Norris, Pippa (2001). Digital Divide. Civic Engagement, Information Poverty, and the Internet

Worldwide. Cambridge University Press.

Norris, Pippa (2000). A Virtuous Cycle. Political Communication in Postindustrial Societies. Cambridge University Press.

Norris, Pippa (2003) Young People \& Political Activism: From the Politics of Loyalties to the Politics of Choice? [Accessed Feb. 2017]. Retrieved from: http://www.hks.harvard.edu/fs/pnorris/Acrobat/COE.pdf $>$.

Nayyar, D. (2007) Modern Mass Communication: Concepts and Processes. Jaipur.

Oxford Book Company.

Neelamalar, M (2010). Media law and ethics

Owen, D. (2008). Election media and youth political engagement. Journal of Social Science Education. Retrieved from www.jsse.org.

Pavlik, John V.(2008). Media in the digital age

Papic, M., \& Noonan, S. (2011). Social media as tool for protest. Security Weekly .Retrieved from http://www.stratfor.com/weekly.

Polat, R.K., 2005. The Internet and Political Participation: Exploring the Explanatory Links.

European Journal of Communication

Soola, O. (1998) Modern Business Communication. Ibadan. Kraft Books Limited.

Pine Forge Press: Thousand Oakes.

Street, J. (2001). Mass Media, Politics and Democracy. New York: Palgrave.

Smith, A, Scholzman, K.L, Verba, S \& Brady, H. 2009. The Internet \& Civic Engagement in Pew Internet \& American Life Project. Retrieved from: http://www.pewinternet.org/Reports/2009/15-The-Internet-andCivic-Engagement.aspx.

Strandberg K. (2006). Parties, Candidates and Citizens Online: Studies of Politics on the Internet.Finland: Åbo Akademi University Press.

William T.(2016), Impact of Social Media on Traditional Journalism: Challenges and Opportunities for Media Houses in Uganda Konrad-Adenauer-Stiftung, Uganda Programme 